\title{
1. A ORIGEM DO PODER JUDICIÁRIO E O PRINCÍPIO DA SEPARAÇÃO DOS PODERES
}

\subsection{Evolução histórica}

A vida em sociedade, desde suas primeiras formas de organização, leva à criação de normas destinadas a permitir a convivência harmônica entre seus membros. O funcionamento adequado dessa forma organizada de vida em sociedade pressupõe o cumprimento dessas normas, e, para isso, há necessidade de mecanismos que assegurem a obediência a este ordenamento jurídico incipiente.

Assim, instituições destinadas a garantir a ordem estabelecida integram os elementos fundamentais para que se considere existir um grupo socialmente organizado.

As primeiras sociedades, ainda que de forma primitiva, criaram mecanismos para solucionar os conflitos entre seus membros e fazer valer a ordem estabelecida.

Dessa necessidade de mecanismos e de instituições destinados a solucionar os conflitos entre as pessoas, a promover a interpretação adequada das normas, bem como da autoridade para exigir seu fiel cumprimento, surgem as primeiras formas do que hoje a maior parte dos Estados modernos convencionou chamar de Poder Judiciário.

O Poder Judiciário, como o conhecemos, tem uma origem que remonta ao próprio surgimento do Estado.

Os primeiros grupos sociais tinham seu mecanismo para cumprir essas funções. No início, a autoridade para exercê-lo era atribuída, na maioria das vezes, aos anciões, para depois ser uma função dos monarcas, até que os grupos sociais foram aumentando, fazendo-se necessária a criação de órgãos responsáveis pelo cumprimento dessas tarefas, órgãos que, por sua vez, tornaram-se maiores e mais complexos ao longo dos tempos, até atingirem as formas pelos quais os conhecemos atualmente. 
Castro Nunes identifica bem essa origem e evolução do Poder Judiciário, partindo da época em que cabia ao Rei acumular as funções de ditar a norma, executá-la e declarar o direito. Esclarece que, com "o andar dos tempos, o desenvolvimento das relações jurídicas e a especialização da função tornada cada vez mais técnica, esse corpo de profissionais [referindo-se aos assessores e conselheiros especializados] veio a constituir uma magistratura a que o Rei foi abandonando, pouco a pouco, o exercício da prerrogativa". ${ }^{1}$

Não é possível estabelecer com precisão a origem do Poder Judiciário, se considerarmos como tal todos os meios pelos quais suas atribuições foram sendo cumpridas ao longo dos tempos. Até mesmo a origem do que hoje consideramos um Estado é pouco nítida.

As primeiras noções sobre o Poder Judiciário, ou a respeito dos órgãos que exerciam as funções que hoje normalmente lhe são confiadas, aparecem com razoável clareza e nitidez nos escritos de Aristóteles.

Em A política, obra na qual discorre sobre a origem do Estado, suas formas de governo e outros assuntos correlatos, Aristóteles (385-322 a.C.), no livro III ("Dos Governos"), capítulo X, trata especificamente "dos três poderes existentes em todo governo": o poder deliberativo, o poder executivo e o poder judiciário. ${ }^{2}$ Vê-se, por suas palavras, já estar à época evidenciada a existência dos três poderes mencionados:

Em todo governo, existem três poderes essenciais, cada um dos quais o legislador prudente deve acomodar da maneira mais conveniente. Quando estas três partes estão bem acomodadas, necessariamente o governo vai bem, e é das diferenças entre estas partes que provêm as suas.

E as funções de cada um deles são bastante semelhantes ao que encontramos hoje:

O primeiro destes três poderes [que ele chama de poder deliberativo] é o que delibera sobre os negócios do Estado. O segundo [denominado de poder executivo] compreende todas as magistraturas ou poderes constituídos, isto é, aqueles de que o Estado precisa para agir, suas atribuições e a maneira de

\footnotetext{
${ }^{1}$ Teoria e prática do Poder Judiciário, p. 47-9.

${ }^{2}$ A política, p. 127-43.
} 
satisfazê-las. O terceiro [chamado de poder judiciário] abrange os cargos de jurisdição. $^{3}$

Mais adiante, ao discorrer sobre o Poder Judiciário, Aristóteles sugere critérios para a escolha dos juízes e para a organização dos tribunais. ${ }^{4}$

São muitas as referências ao Poder Judiciário surgidas posteriormente; algumas merecem especial destaque.

No século XVII, John Locke, em sua obra Segundo Tratado sobre o Governo, menciona, no capítulo XII, "os poderes legislativo, executivo e federativo da comunidade". Ao poder legislativo, cabe "a tarefa de definir o modo que se deverá utilizar a força da comunidade para a preservação dela própria e dos seus membros". 5 Ao poder executivo, cabe executar as leis em vigor. E o terceiro, que ele sugere chamar de "poder federativo", resulta da necessidade que a comunidade tem de resolver as controvérsias entre um membro da sociedade e os que estão fora dela, bem como de ter um mecanismo para reparar danos causados aos membros dessa sociedade. ${ }^{6}$

A consagração da teoria de organização do Estado com os poderes separados ocorreu com a obra Do espírito das leis, de Montesquieu, em 1748. Montesquieu inicia sua obra reconhecendo ser uma lei natural o desejo dos homens de viver em sociedade. Essa reunião, no entanto, faz surgir um estado de guerra entre eles, tornando necessário o estabelecimento de leis. ${ }^{7}$ Procura estudar, em sua obra, as diversas relações que as leis mantêm com a natureza, os governos e as pessoas. No livro II, discorre sobre as leis nas três espécies de governo que reconhece: o republicano, o monárquico e o despótico. Fixa os três princípios que regem cada um desses governos: a república guia-se pelo princípio da virtude, a monarquia, pela honra, e o governo despótico, pelo medo. ${ }^{8}$ baseado nesses princípios, estuda os diversos tipos de leis em cada espécie de governo. Ao atingir o livro XI, passa a analisar as leis que formam a liberdade política e sua relação com a Constituição. Neste ponto é que surgem as ideias fundamentais de

\footnotetext{
${ }^{3}$ Idem, p. 127.

${ }^{4}$ Idem, p. 141-3.

${ }^{5}$ Segundo Tratado sobre o Governo, p. 106.

${ }^{6}$ Idem, p. 107.

${ }^{7}$ Do espirito das leis, p. $20-1$.

${ }^{8}$ Idem, p. 43.
} 
Montesquieu para a doutrina da separação dos poderes. Cabe destacar, inicialmente, a definição de "liberdade política", que, segundo ele, "não pode consistir senão em poder fazer o que se deve querer, e em não ser constrangido a fazer o que não se deve desejar". Em seguida, reconhece a dificuldade em assegurar-se esta liberdade: "a experiência eterna nos mostra que todo homem que tem poder é sempre tentado a abusar dele; e assim irá seguindo, até que encontre limites". ${ }^{9}$ Logo após, conclui: "Para que não se possa abusar do poder, é preciso que, pela disposição das coisas, o poder contenha o poder". Para ilustrar seu pensamento, passa a fazer referência à Constituição do Estado da Inglaterra, que, de acordo com ele, tem por objetivo direto a liberdade política. Mostra haver uma separação em três espécies de poder: “O poder legislativo, o poder executivo das coisas que dependem do direito das gentes, e o poder executivo daquelas que dependem do direito civil". ${ }^{10}$ A este último, cabe a tarefa de punir os crimes e julgar as questões dos indivíduos, sendo denominado por ele "poder de julgar". ${ }^{11}$ Passa, então, a expor as razões que o levam a concluir sobre a necessidade de separação dos poderes do Estado, a fim de que se possa assegurar a almejada liberdade política, em trecho que vale ser transcrito:

\begin{abstract}
Quando em uma só pessoa, ou em um mesmo corpo de magistratura, o poder legislativo está reunido ao poder executivo, não pode existir liberdade, pois se poderá temer que o mesmo monarca ou o mesmo senado criem leis tirânicas para executá-las tiranicamente. Também não haverá liberdade se o poder de julgar não estiver separado do poder legislativo e do executivo. Se o poder executivo estiver unido ao poder legislativo, o poder sobre a vida e a liberdade dos cidadãos seria arbitrário, pois o juiz seria o legislador. E se estiver ligado ao poder executivo, o juiz poderia ter a força de um opressor. Tudo então estaria perdido se o mesmo homem, ou o mesmo corpo dos principais, ou o dos nobres, ou o do povo, exercesse estes três poderes: o de criar as leis, o de executar as resoluções públicas e o de julgar os crimes e as querelas dos particulares. ${ }^{12}$ (grifo nosso)
\end{abstract}

Esse pensamento é de fundamental importância, pois influenciou a formação dos Estados modernos, consagrando a existência de três poderes distintos, com funções próprias a cada um, e que devem agir harmonicamente para assegurar a liberdade política.

\footnotetext{
${ }^{9}$ Idem, p. 164.

${ }^{10}$ Idem, p. 165. Direito civil, segundo Montesquieu, é aquele concernente às leis que regulam as relações que todos os cidadãos mantêm entre si (Do espírito..., p. 21).

${ }^{11}$ Idem, p. 165.

${ }^{12}$ Idem, p. 166.
} 
Assim, embora a origem do Poder Judiciário, no que tange às funções exercidas, seja remota e difícil de estabelecer com precisão, a sua institucionalização como um dos poderes independentes do Estado tornou-se mais clara a partir da divulgação das ideias de Montesquieu, as quais vieram a ser aplicadas pouco tempo depois, como se pode constatar na Constituição dos Estados unidos da América, de 1787, que prevê um Poder Legislativo (art. I), um Poder Executivo (art. II) e um Poder Judiciário (art. III). ${ }^{13}$

A Declaração dos Direitos do Homem e do Cidadão, elaborada pela Assembleia Nacional francesa, em 1789, estabelece, no enunciado 16, que "toda sociedade na qual não se assegura a garantia dos direitos, nem se determina a separação dos poderes, considera-se desprovida de constituição".

Consolidou-se, dessa forma, a teoria da separação dos poderes, acolhida de modo claro pela Constituição brasileira. No entanto, passou a ser questionada e até hoje é alvo de críticas, algumas das quais serão objeto de referência a seguir.

\subsection{Críticas à teoria da separação dos poderes}

Cumpre ressaltar que a doutrina da separação dos poderes é discutida por vários estudiosos do assunto e sua importância é mitigada em alguns Estados. Há autores que já fazem referência a outras formas de separação dos poderes do Estado, como Loewenstein; outros entendem que deve haver apenas uma divisão de funções com a finalidade de desconcentrar o poder, como Kelsen; Tércio Sampaio Ferraz considera a separação de poderes um princípio em decadência; e há também defensores da tese de que a teoria de Montesquieu foi mal interpretada, como Eros Grau e Gilberto Bercovici.

\footnotetext{
${ }^{13}$ A Suprema Corte dos EUA já se manifestou sobre a questão, tornando mais clara a adoção deste princípio: "It is believed to be one of the chief merits of the American system of written constitutional law, that all the powers intrusted to government, whether State or National, are divided into the three grand departments, the executive, the legislative and the judicial. That the functions appropriate to each of theses branches of government shall be vested in a separate body of public servants, and that the perfection of the system requires that the lines which separate and divide these departments shall be broadly and clearly defined. It is also essential to the successful working of this system that the persons intrusted with power in any of these branches shall not be permitted to encroach upon the powers confided to others, but that each shall by the law of its creation be limited to the exercise of the powers appropriate to its own department and no other" [Kilbourn v. Thompson, 103 U.S. 168, 190-1, 1880 (In: FRIEDRICH, Carl Joachim. Separation of powers, p. 663)].
} 
Loewenstein considera antiquada a teoria da separação dos poderes. Por isso, propõe uma nova divisão, também tripartida: "la decisión política conformadora o fundamental (policy determination), la ejecución de la decisión (policy execution) y el control político (policy control)". ${ }^{14}$ Ressalta, inicialmente, a necessidade de tomarem-se as decisões políticas fundamentais, consideradas como tais aquelas resoluções da sociedade determinantes para o presente e para o futuro, que darão a forma da comunidade, cujo primeiro e principal mecanismo é por meio da legislação. Há de se executar essas decisões, o que se faz pela Administração Pública e também pelo exercício da função judicial. Por fim, deve haver um controle político, que se faz mediante a atribuição de diferentes funções estatais a distintos detentores do poder e órgãos do Estado, dotados de autonomia. ${ }^{15}$ Justifica, assim, a necessidade de modificar a divisão tripartida dos poderes hoje utilizada.

Para Kelsen, existem não três, mas apenas duas funções básicas do Estado, quais sejam, a criação e a aplicação do Direito, não sendo possível estabelecer fronteiras nítidas entre elas, nem criar órgãos que exerçam essas funções com exclusividade. Kelsen evidencia as situações de interpenetração das funções entre os atuais três poderes, demonstrando as deficiências desta divisão, para defender que o princípio da separação dos poderes "opera antes contra uma concentração que a favor de uma separação de poderes". ${ }^{16}$

O princípio da divisão de poderes, com um Poder Judiciário autônomo, nas palavras de Tércio Sampaio Ferraz, surgiu como um mecanismo eficiente para evitar o despotismo real então vigente, sendo esse o sentido que Montesquieu pretendeu dar em seu trabalho. Para isso, a neutralidade política do Judiciário mostrou-se uma peça importante na caracterização do Estado de Direito, permitindo a "substituição da unidade hierárquica, concretamente simbolizada pelo rex, por uma estrutura complexa de comunicação e controle de comunicação entre forças mutuamente interligadas"17, constituindo-se em verdadeira "espinha dorsal do Estado de Direito burguês". Observa, em seguida, que a sociedade tecnológica avançou muito, aumentando o nível de

\footnotetext{
${ }^{14}$ Teoría de la constitución, p. 62.

${ }^{15}$ Idem, p. 63-72.

${ }^{16}$ Teoria geral do Direito e do Estado, p. 385-404.

${ }^{17}$ O Judiciário frente à divisão dos poderes: um princípio em decadência?, p. 41.
} 
complexidade da vida humana, o que tem feito com que as atividades de controle deixem de voltar-se para o passado e passem a se ocupar do futuro. Os tribunais são chamados a fazer uma avaliação prospectiva, projetando o Direito para o futuro, refletindo o crescimento do Estado do bem-Estar Social, do avanço dos direitos sociais, e tendo de decidir sobre ações de caráter coletivo que reflitam políticas públicas asseguradoras desses direitos. Isso leva a uma desneutralização política do juiz e a uma politização da Justiça, tornando necessária uma reflexão sobre a teoria da separação dos poderes, que, nas palavras de Hans Girardi, passa a não ter hoje a mesma relevância de outras épocas. ${ }^{18}$

Eros Grau, ao explicar o exercício da função normativa pelo Poder Executivo, tece importantes e interessantes considerações críticas sobre a teoria da separação dos poderes, sendo relevante sintetizar suas ideias a respeito do tema. De início, ressalta que Montesquieu não sustenta a impenetrabilidade entre os poderes, reconhecendo que uns, por vezes, exercem funções típicas de outro; o filósofo francês, na verdade, cogita de uma distinção entre eles, que devem atuar em equilíbrio. Em seguida, discorre sobre a distinção entre poder e função, explicando que o poder "é expressão de uma capacitação para efetivamente realizar ou impor a realização de determinado fim" ${ }^{19}$, sendo o poder estatal o poder político juridicamente organizado. Esse poder estatal se traduz em uma função, que pode ser vista no aspecto institucional, material ou subjetivo. No aspecto institucional, as funções podem ser classificadas em legislativa, executiva e jurisdicional; no aspecto material, em função normativa (produção das normas jurídicas - que equivalem aos textos normativos), administrativa (execução das normas jurídicas) e jurisdicional (aplicação das normas jurídicas); e no aspecto subjetivo, nos Poderes Legislativo, Executivo e Judiciário, que são "os centros ativos de funções, ou seja, os órgãos incumbidos de sua execução". ${ }^{20}$ Explicitando o conteúdo da função normativa, conceitua norma como sendo:

[...] o preceito, abstrato, genérico e inovador - tendente a regular o comportamento social de sujeitos associados - que se integra no ordenamento jurídico, [constituindo-se em] um preceito primário, no sentido de que se impõe por força própria, autônoma; [sendo assim, por função

\footnotetext{
${ }^{18}$ Idem, p. 44-8.

${ }^{19}$ O direito posto e o direito pressuposto, p. 236.

${ }^{20}$ Idem, p. 236-7.
} 
normativa] deve entender-se aquela de emanar estatuições primárias - isto é, operantes por força própria - contendo preceitos abstratos. ${ }^{21}$ (grifos do original)

Mostra que a função normativa, ora explicitada, não se confunde com a função legislativa, que emana "estatuições primárias, geralmente - mas não necessariamente com conteúdo normativo, sob a forma de lei”. Isto ocorre porque os conceitos de lei e norma não se confundem.

\begin{abstract}
Norma é todo preceito expresso mediante estatuições primárias (na medida em que vale por força própria, ainda que eventualmente com base em um poder não originário, mas derivado ou atribuído ao órgão emanante), ao passo que lei é toda estatuição, embora carente de conteúdo normativo, expressa, necessariamente com valor de estatuição primária, pelos órgãos legislativos ou por outros órgãos delegados daqueles. A lei não contém, necessariamente, uma norma. Por outro lado, a norma não é necessariamente emanada mediante uma lei. E, assim, temos três combinações possíveis: a leinorma, a lei não norma e a norma não lei. ${ }^{22}$
\end{abstract}

Com isso, mostra que o Poder Executivo, quando exerce função regulamentar, esta não decorre de uma delegação da função legislativa, mas de exercício da função normativa, que compreende as funções legislativa e regulamentar. Conclui, ao final, que a "interpenetração de funções deixa bem evidenciada, neste passo, a face real da exposição de Montesquieu, atinente ao equilibrio e não à 'separação' de poderes". ${ }^{23}$

Gilberto Bercovici, analisando o princípio da separação dos poderes nos Estados unidos, extrai dos textos dos "Artigos federalistas" a ideia de que os Poderes Legislativo, Executivo e Judiciário não devem ser inteiramente desvinculados uns dos outros; na verdade, deve haver interpenetração, de modo que cada um controle os demais. O mecanismo utilizado pela Constituição americana não foi o da separação absoluta e total dos poderes, mas o sistema de freios e contrapesos. Assevera que não foi o que ocorreu no caso do Brasil, que adotou o sistema de separação de poderes no ordenamento constitucional por meio da interpretação literal, e, em sua opinião, equivocada, de Montesquieu. ${ }^{24}$

\footnotetext{
${ }^{21}$ Idem, p. 239-40.

${ }^{22}$ Idem, p. 241.

${ }^{23}$ O direito posto..., p. 225-55.

24 “Separação de poderes" no Estado federal norte-americano, p. 227-230.
} 
Carl Friedrich, ao discorrer sobre o tema, lembra que, embora os Estados unidos consagrem a separação de poderes como um princípio constitucional fundamental, a expansão das agências reguladoras, que praticamente realizam atos legislativos, executivos e judiciais, tem mitigado sua importância e colocado em dúvida a necessidade desse princípio para garantir a liberdade. Cita o exemplo da Inglaterra, em que a intensa interpenetração dos Poderes Executivo e Legislativo não parece ter destruído os fundamentos de um governo livre. ${ }^{25}$

\subsection{A separação de poderes e o sistema de freios e contrapesos}

James Madison, um dos autores da obra $O$ federalista, reconhece que a acumulação de todos os poderes (Executivo, Legislativo e Judiciário) nas mesmas mãos pode caracterizar tirania, como defendido por Montesquieu; no entanto, considera haver interpretação distorcida de suas ideias, sendo a verdadeira interpretação de seu pensamento a de que "onde todo o poder de um dos ramos é concentrado nas mesmas mãos que enfeixam todo o poder de outro ramo, os princípios fundamentais de uma Constituição livre estarão subvertidos". ${ }^{26}$

Não há, em sua tese, separação absoluta dos poderes, sendo até necessária uma representação parcial de um poder em outro ou controle mútuo dos respectivos atos. Não se deve permitir que qualquer dos poderes possua, direta ou indiretamente, influência dominante sobre os demais no exercício dos poderes próprios de cada um; ressalta também que "os poderes específicos de um dos ramos não devem ser direta e integralmente exercidos por qualquer dos outros dois". A tarefa mais difícil, segundo Madison, “está em prover para cada um deles certa segurança prática contra invasões por parte dos outros. Como será tal segurança - eis o grande problema a ser resolvido". Madison, de forma precisa e inteligente, resumiu nessa sua colocação um problema central na doutrina da separação dos poderes. ${ }^{27}$

Os Estados Unidos da América, em sua Constituição, consagraram a teoria dos freios e contrapesos (checks and balances), separando os poderes em órgãos distintos,

\footnotetext{
${ }^{25}$ Separation of powers, p. 664.

${ }^{26}$ HAMILTON; MADISON; JAY. O federalista, p. 302.

${ }^{27}$ Idem, p. 301-7.
} 
com autonomia e independência, estabelecendo também um controle recíproco, evitando a concentração de poder. ${ }^{28}$

Sem querer seguir o exemplo inglês da monarquia, sistema que repudiavam ${ }^{29}$, os Estados unidos adaptaram as ideias de Montesquieu, que defendia o Poder Executivo nas mãos do monarca, criando o sistema presidencialista de governo. Mantiveram o Poder Executivo nas mãos de uma única pessoa, que passou a ser o Presidente da República, eleito democraticamente pela população, para um período determinado (no caso, de quatro anos - Constituição dos EUA, art. II, seção 1).

A interpenetração dos poderes, com funções típicas de um poder sendo exercidas por outro, em determinados casos, ou mesmo formas indiretas de influência, como um escolhendo membros que integram o outro, é fato inconteste, que ocorre nos Estados que adotam o sistema da tripartição nítida dos poderes. ${ }^{30} \mathrm{O}$ sistema de freios e contrapesos faz surgir também uma série de mecanismos de controle de um poder sobre o outro, evidenciando a relatividade do conceito de separação entre os poderes. ${ }^{31}$ Isso, no entanto, nunca chegou a macular a teoria da tripartição dos poderes. É inegável, mesmo se adotando sistemas que preveem claramente a separação dos poderes, como se vislumbra no caso brasileiro, não haver uma independência absoluta entre eles. A independência será sempre relativa, até porque o Estado é uno, soberano e indivisível. Vários autores deixam clara essa noção. Hely Lopes Meirelles, ao explicitar as ideias de Montesquieu, afirma:

Aliás, já se observou que Montesquieu nunca empregou em sua obra política as expressões "separação de Poderes" ou "divisão de Poderes", referindo-se unicamente à necessidade do "equilíbrio entre os Poderes", do que resultou

\footnotetext{
${ }^{28}$ Modelo que veio servir de base para a organização de diversos Estados modernos, como o Brasil.

${ }^{29}$ Em sua Declaração de Independência, de 4 de julho de 1776, os americanos mostram-se bastante revoltados com a monarquia inglesa: "The history of the present King of Britain is a history of repeated injuries and usurpations, all having in direct object the establishment of an absolute Tyranny over these States".

${ }^{30}$ A Constituição brasileira prevê, por exemplo, a escolha dos membros do STF pelo Presidente da República com aprovação do Senado Federal (art. 101, parágrafo único); a edição de medidas provisórias pelo Presidente da República (art. 62); julgamento do Presidente da República por crimes de responsabilidade pelo Senado Federal (art. 52, I); a elaboração, pelo Presidente da República, das leis delegadas (art. 68), além de outras.

31 A Constituição brasileira traz algumas situações que permitem vislumbrar os mecanismos de freios e contrapesos: é o caso do poder de veto do Presidente da República (art. 66, $\S 1^{\circ}$ ), a aprovação pelo Senado Federal da escolha de ocupantes de cargos públicos nos Poderes Executivo e Judiciário (art. 53, III), a fiscalização da administração pública pelo Poder Legislativo (art. 70), etc.
} 
entre os ingleses e norte-americanos o sistema de checks and balances, que é o nosso método de freios e contrapesos, em que um Poder limita o outro, como sugerira o próprio autor no original: "le pouvoir arrête le pouvoir". Seus apressados seguidores é que lhe deturparam o pensamento e passaram a falar em "divisão" e "separação de Poderes", como se estes fossem estanques e incomunicáveis em todas as suas manifestações, quando, na verdade, isto não ocorre, porque o Governo é a resultante da interação dos três Poderes de Estado - Legislativo, Executivo e Judiciário - como a Administração o é de todos os órgãos desses Poderes. ${ }^{32}$

Castro Nunes, embora veja nas ideias de Montesquieu uma nítida separação de poderes, também reconhece a relatividade do princípio: “O princípio não é, pois, absoluto. Isso, porém, não envolve a sua negação, ainda que sem a rigidez do conceito de Montesquieu, porque de outro modo não haveria o Estado constitucional, que se define, histórica e politicamente, por essa separação". ${ }^{33}$

No mesmo sentido posiciona-se Rosalina Correa de Araújo. ${ }^{34}$ José Afonso da Silva interpreta as interferências como meios de se assegurar a harmonia necessária entre os poderes, sintetizando com notável precisão as ideias ora veiculadas:

\begin{abstract}
A harmonia entre os poderes verifica-se primeiramente pelas normas de cortesia no trato recíproco e no respeito às prerrogativas e faculdades a que mutuamente todos têm direito. De outro lado, cabe assinalar que nem a divisão de funções entre órgãos do poder nem sua independência são absolutas. Há interferências, que visam ao estabelecimento de um sistema de freios e contrapesos, à busca do equilíbrio necessário à realização do bem da coletividade e indispensável para evitar o arbítrio e o desmando de um em detrimento do outro e especialmente dos governados. ${ }^{35}$
\end{abstract}

Do exposto, constata-se que a separação de poderes é um princípio adotado na maior parte dos Estados modernos, sem que, no entanto, seja possível considerá-lo absoluto, na medida em que há uma interpenetração, com situações de exercício de funções que não são próprias a cada um dos poderes considerados. Além disso, há mecanismos de controle recíproco, caracterizadores do sistema de freios e contrapesos, que visam evitar a concentração de poder e, consequentemente, a ocorrência de abusos, conforme alerta Montesquieu.

\footnotetext{
${ }^{32}$ Direito Administrativo brasileiro, p. 57.

${ }^{33}$ Teoria e prática..., p. 51.

${ }^{34}$ O Estado e o Poder Judiciário no Brasil, p. 447.

${ }^{35}$ Curso de Direito Constitucional positivo, p. 111.
} 
Com isso, evidencia-se a existência de diferenças no grau de independência e autonomia que os Estados conferem a cada um dos poderes. Em alguns Estados, como o Brasil, há uma maior independência; em outros, como os que adotam o sistema parlamentarista, essa independência é menor.

\subsection{A separação de poderes e o sistema parlamentarista}

As diferentes formas de organização do Estado, com maior ou menor clareza na divisão dos poderes, permitem até que se classifiquem os diversos sistemas de governo, como Manoel Gonçalves Ferreira Filho faz, em três categorias:

a) sistema de concentração do poder, no qual não há divisão do poder, citando como exemplo o antigo regime soviético;

b) sistema de colaboração de poderes, no qual há a divisão formal em três poderes, mas esses não são independentes, citando como exemplo os Estados que adotam o sistema parlamentarista; e

c) sistema de separação de poderes, no qual há claramente três poderes independentes, como em geral ocorre nos Estados que adotam o sistema presidencialista. ${ }^{36}$

Essas diferenças vão influenciar as várias formas pelas quais os Estados tratam da autonomia do Poder Judiciário, notando-se haver um grau mais elevado de autonomia nos Estados em que vigora o sistema presidencialista do que naqueles sob a égide do parlamentarismo. Nestes, o grau de independência dos poderes é pequeno, tornando sua tripartição pouco nítida.

O parlamentarismo, como assevera Dalmo Dallari, "foi produto de uma longa evolução histórica, não tendo sido previsto por qualquer teórico, nem se tendo constituído em objeto de um movimento político determinado". ${ }^{37}$ Surgiu para acomodar interesses dos detentores do poder na Inglaterra a partir do século XIII, atingindo seu apogeu com a Revolução Inglesa, em 1688 e 1689, quando o Parlamento impõe-se

\footnotetext{
${ }^{36}$ Curso de Direito Constitucional, p. 129.

${ }^{37}$ Elementos de Teoria Geral do Estado, p. 231.
} 
como força política. ${ }^{38}$ Caracteriza-se pela separação da função de chefe de Governo, exercida pelo Primeiro-Ministro, indicado pelo Parlamento, a quem cabe exercer o Poder Executivo, e a função de chefe de Estado, a quem cabe exercer, basicamente, funções de representação. No sistema parlamentarista, há interpenetração significativa dos Poderes, especialmente entre Legislativo e Executivo, mitigando a relevância da tripartição de poderes. A divisão das funções do Estado nos três poderes já consagrados mantém-se, mas não há uma preocupação em reconhecer-lhes uma independência institucional nos moldes constatados em países que adotam o sistema presidencialista.

$\mathrm{Na}$ França, que adota o regime parlamentarista, o Poder Legislativo é constituído pela Assembleia Nacional e pelo Senado (Constituição, art. 24). O Governo é dirigido pelo Primeiro-Ministro (art. 21), nomeado pelo Presidente da República (art. 8), e este preside o Conselho de Ministros. Há um Conselho Constitucional (Conseil Constitutionnel), composto de nove membros nomeados pelo Presidente da República, pelo Presidente da Assembleia Nacional e pelo Presidente do Senado (art. 56). Este Conselho decide sobre questões relacionadas à eleição do Presidente da República, Deputados, Senadores e referendos, bem como avalia a constitucionalidade das leis. O art. 64 da Constituição francesa regula a "Autoridade Judicial" (Autorité Judiciaire) e estabelece que compete ao Presidente da República garantir a independência da autoridade judicial, assistido pelo Conselho Superior da Magistratura, o qual é presidido pelo próprio Presidente da República e tem como vice-presidente o Ministro da Justiça. $\mathrm{O}$ art. 67 prevê o Alto Tribunal de Justiça (Haute Cour de Justice), composto de membros eleitos pela Assembleia Nacional e pelo Senado. Vê-se, claramente, que no sistema adotado a interpenetração entre os poderes é intensa, sendo bastante mitigada a separação entre o Executivo, o Legislativo e o Judiciário.

Na Itália, o Poder Legislativo (Parlamento) compõe-se da Câmara dos Deputados e do Senado da República (Constituição, art. 55); o Presidente da República é eleito pelo Parlamento (art. 83) e exerce as funções de Chefe de Estado (art. 87), sendo o Governo chefiado pelo Presidente do Conselho de Ministros (art. 95). O Poder Judiciário (que consta na Constituição sob o título de "Magistratura") constitui um órgão autônomo e independente dos demais poderes (art. 104), havendo, no entanto, um

\footnotetext{
${ }^{38}$ Idem, p. 232.
} 
Conselho Superior da Magistratura, a quem compete decidir sobre admissão, promoção, remoção e aplicação de medidas disciplinares relacionadas aos magistrados, sendo este órgão presidido pelo Presidente da República e composto por magistrados, professores universitários e advogados. Há, também, embora em menor intensidade que na França, uma interpenetração significativa entre os poderes.

A Constituição portuguesa considera "órgãos de soberania" o Presidente da República, a Assembleia da República, o Governo e os Tribunais (Constituição, art. 113, 1), que devem observar separação e independência (art. 114, 1). O Presidente da República exerce funções de chefe de Estado (art. 123), competindo-lhe nomear e exonerar o Primeiro-Ministro e os membros do Governo (art. 136, f). O Primeiro-Ministro é o chefe do Governo (art. 186), sendo nomeado pelo Presidente da República, após ouvidos os partidos representados na Assembleia da República e tendo em vista os resultados eleitorais (art. 190, 1). Os demais membros do Governo são nomeados pelo Presidente da República sob proposta do Primeiro-Ministro (art. 190, 2). O Poder Legislativo é exercido pela Assembleia da República, composta de Deputados eleitos por sistema de representação proporcional (arts. 150 a 155). O Poder Judiciário é exercido pelos Tribunais, órgãos dotados de soberania (art. 205, 1) e independência (art. 206). Há um Tribunal Constitucional, composto por 13 membros, Juízes e juristas, sendo dez escolhidos pela Assembleia da República; o Presidente do Tribunal Constitucional é eleito pelos respectivos Juízes (art. 224). É interessante notar que em Portugal o Supremo Tribunal de Justiça, órgão superior da hierarquia dos tribunais judiciais, tem seu presidente eleito pelos respectivos Juízes (art. 212, 1 e 2), que também preside o Conselho Superior da Magistratura, cujos membros são eleitos pelo Presidente da República, pela Assembleia da República e pelos Juízes.

Vê-se, pelos exemplos citados, que cada Estado tem sua forma peculiar de organização, havendo diversos meios de relacionamento entre os poderes. Mesmo nos que adotam o regime parlamentarista, embora se note uma interpenetração maior entre eles, esta ocorre de diferentes formas, com maior ou menor autonomia para os poderes. 


\subsection{A separação de poderes no sistema constitucional brasileiro}

O modelo adotado pelo Estado brasileiro, expresso em sua Constituição, não deixa dúvidas sobre a adoção do princípio da separação dos poderes como base da sua organização. A Constituição estabelece, no art. $2^{\circ}$, que os poderes são independentes, e o art. $60, \S 4^{\circ}$, III, veda emendas à Constituição que possam abolir a separação de poderes, tornando este dispositivo "cláusula pétrea". E vai mais além, ao estabelecer que a organização do Estado brasileiro pressupõe a independência e a autonomia do Poder Judiciário frente aos demais poderes, sendo esta autonomia ampla, abrangendo os aspectos administrativo e financeiro, conforme expressamente previsto no art. 99 da CF.

Assim, dada a forma explícita com que a Constituição consagrou a separação dos poderes, cabe ao operador do Direito compreender nosso ordenamento jurídico e aplicá-lo tendo por base este princípio.

O modelo adotado pelo Poder Judiciário brasileiro, bem como a compreensão exata dos conceitos de independência e autonomia, expressamente mencionados no texto constitucional, são questões importantes para o objeto desta tese, a ser estudada com maior profundidade, o que será feito nos itens subsequentes, após situarmos o Poder Judiciário no contexto do Estado e da Administração Pública. 